\title{
Multi-sensory storytelling (MSST): a tool for teaching or an intervention technique?
}

David Preece \& Yu Zhao

Centre for Education and Research

School of Education

University of Northampton

Contact: david.preece@northampton.ac.uk

\section{Author details:}

David Preece is a Senior Lecturer within the Centre for Education and Research in the School of Education at the University of Northampton.

Yu Zhao is a Research Assistant within the Centre for Education and Research in the School of Education at the University of Northampton

\section{Introduction}

Multi-sensory storytelling (MSST) is an approach to storytelling in which 'stories are not simply told but can be experienced with all our senses (Fornefeld, 2013, p78). The act of narration is supported by the use of relevant objects, chosen for their sensory qualities (e.g. feel, smell, sound, weight, temperature) and for their appeal and relevance to those experiencing the story. MSST was first conceptualised as a specific approach in the late 1980 s by Fuller (Fuller, 2013). Since this time, MSST has been identified as an enjoyable activity for children, young people and adults with profound and multiple learning difficulties (PMLD) (Fuller, 1999) - as well as for others with special educational needs and disabilities (SEND) - and is regularly used with younger children, older children and adults (Boer and Wikkerman, 2008).

In recent years, there has been increasing interest within the UK and Europe regarding the use of MSST, particularly in the field of special education (Lawson et al., 2012; Grove et al., 2015). The literature suggests that such stories can support the development of literacy skills in PMLD (Fornefeld, 2013; Watson, 2002) and provide such individuals with opportunities for interaction and enjoyment (Park, 2013). Many schools and individual teachers have adapted their own multi-sensory versions of existing stories, developed their own stories to suit a particular need, or both. Furthermore, commercially produced multisensory stories are also available both as complete activities (e.g. 'Bag Books' and 'Story Sacks' in the UK, 'mehr-Sinn $\AA$ Geschichten' in Germany) and as scripts (Arnold, 2013; Grace, 2014). As a result the approach is being used 'frequently and enthusiastically' across a range of settings with children and adults (Vlaskamp et al., 2011, p.107)'.

Studies have been undertaken by researchers associated with the Profound and Multiple Impairment Service (PAMIS) to evaluate the impact of MSST in helping individuals with PMLD deal with and understand sensitive issues, including living with epilepsy, undergoing dental treatment and managing sexual behaviour (Lambe and Hogg, 2011, 2013; Lambe et al., 2014; Young \& Lambe, 2011; Young et al. 2011). Further research in the United Kingdom using the Storysharing ${ }^{\circledR}$ approach has identified that MSST can be used to support the development of both fictional stories and personal narratives (Grove, 2014; 
Grove et al., 2015). Research undertaken in the Netherlands and Flanders has focused on adherence to storytelling guidelines and protocols (Penne et al., 2011; ten Brug et al., 2012; Vlaskamp et al., 2011), and staff behaviour in interaction during storytelling (Penne et al., 2012). However, there has been little if any research focused on more fundamental questions regarding MSST: how, why, where, when and with whom this approach is being used so 'frequently and enthusiastically'. Therefore the research questions addressed within this study were:

- How are multi-sensory stories (either 'home-made' or commerciallyproduced) used within day-to-day practice in the classroom and school?

- What opportunities does the approach provide, and what factors affect its use?

\section{Method}

An exploratory case study methodology was identified as appropriate to research this relatively new area of investigation (Mills et al., 2010). It has been identified that the most likely educational placement for children with PMLD or SLD (those with whom MSST are typically used) is a special school (Male, 2015): therefore data collection was restricted to such settings. Semi-structured interviews were carried out with school-based professionals to investigate their attitudes towards and understanding of MSST. Unstructured observations of storytelling sessions allowed the researchers to see how these professionals used MSST in practice, and to observe the extent to which they followed guidelines and their practice aligned with the existing literature.

\section{Sample}

Data were collected from 5 special schools in the East Midlands and South-East of England. All schools self-identified as having made extensive use of multisensory stories, both those developed by school staff and commercially produced stories. Purposive sampling was used to select the research sites, to ensure that a range of potential settings and students were considered. Selection criteria comprised:

- school type (day/residential)

- range of SEND addressed (e.g. PMLD, multiple disabilities and visual impairments (MDVI), severe learning difficulties (SLD), social/emotional/behavioural difficulties (SEBD), visual impairment (VI) and autism)

- age range (primary/up to 19 years)

- location (different local authorities, urban/suburban).

\section{Data collection}

Twenty-seven interviews were conducted with school-based professionals, whose experience of using MSST ranged from $<1$ year to $>10$ years or more. Interview data were collected in individual semi-structured interviews, digitally recorded at the school sites. Interviewees comprised:

- 17 class teachers

- 6 teaching assistants

- 1 x Deputy Head Teacher

- 1 x Head of Post-16 Education

- 1 x School Librarian 
- $1 \times$ coordinator of a charity providing a library service for children with visual impairments.

Observations were undertaken of 18 sessions where teachers were using MSST as part of the typical school day. The observations were conducted using nonparticipant unstructured observation techniques with field notes made in situ. Storytelling sessions varied in length from 5 to 35 minutes, with a median length of 20 minutes. These comprised:

- 2 x Early Years Foundation Stage ( $1 \times$ PMLD, I x mixed PMLD/SLD)

- 4 x Key Stage 1 ( $2 \times$ PMLD, $1 \times$ MSI/PMLD, $1 \times$ PMLD/SLD)

- 4 x Key Stage 2 ( $2 \times$ PMLD, $1 \times$ PMLD/SLD/autism, $1 \times$ autism/SEBD)

- 4 x Key Stage 3 ( $3 \times$ PMLD, $1 \times$ mixed SLD/VI)

- $2 \times$ Key Stage 4 (PMLD)

- $1 \times$ Post-16 (PMLD)

- $1 x$ whole school assembly.

\section{Ethics}

The research was undertaken in accordance with the British Educational Research Association's Ethical Guidelines for Educational Research (BERA, 2011). Informed, voluntary written consent was obtained from all adults interviewed, and interviewees were made aware that they could withdraw from the research at any time. The students with whom MSST was being used had severe or profound learning disabilities: this limited their ability to understand or agree to participate in the research. Informed, voluntary written consent was therefore obtained the parents of all students in the story-telling sessions for the researchers to be present. The MSST sessions were carried out 'as normal', led by the teacher and support staff, who were familiar with the ways in which the children conveyed assent and dissent (Wiles, 2013). It was agreed that observation would stop, and the researchers would leave the room, if it was felt by any adult that the researchers' presence was causing anyone any discomfort or distress. The recorded interviews were professionally transcribed and anonymised, and all data were securely stored.

\section{Data analysis}

Transcripts of the interviews and the records of the observations were analysed using thematic coding analysis (King, 2004). An a priori list of predetermined codes was derived from the research questions and literature (Basit, 2003). These served as an initial template, with additional inductive coding emerging through the process of analysis. Coding of transcripts/observation records was undertaken by one researcher and audited for exhaustiveness and appropriateness by the other, and codes were reviewed for overlap and redundancy. Data were then further reduced into matrices, condensing the key themes. These are considered below in the light of the research questions and in relation to the literature.

\section{Findings}

How are multi-sensory stories (either 'home-made' or commerciallyproduced) used within day-to-day practice in the classroom and school?

'Sometimes they'll be used as a basis of a lesson. Sometimes they will be used to build up, say, a student's touch skills. Or it might because the rest of the class is doing painting or collage and this is perhaps 
more appropriate for them. Or it might be because the whole class had a really good maths lesson and then it's like a post-lesson reward.'

This study identified that MSST was being used across the whole school environment and beyond, and across a wide range of students. Multi-sensory stories were used indoors and outside, in the classroom, on holiday play scheme activities, and were shared with parents for use at home and with residential settings. MSST was used not only as a teaching tool, but also to entertain students waiting for school transport to arrive, to while away wet play times and as an activity for gastrostomy-fed students at lunchtime. MSST was used with large groups, small groups and in individual storytelling sessions, not only with students with PMLD but also with those with a range of other difficulties ( 7 of the 18 MSST sessions observed were with mixed groups of students).

MSST was seen as particularly important in the teaching of English and Literacy, in making drama accessible, and supporting the development of communication. A wide range of adapted stories were in use (including fairy tales, the works of Shakespeare and H.G. Wells' 'The War of the Worlds') in addition to commercially-produced multi-sensory stories and teachers' own creations. Many teachers also used the approach more broadly: MSST was also observed being used in Religious Education, Geography, Personal, Social and Health Education (PSHE) and Science lessons, while interviews further provided examples of its utility.

'In my class particularly, everything has to have a sort of a sensory base, you know. Everything we do really in this class is a story with props to make it more accessible.'

\section{What opportunities does the approach provide, and what factors affect its use?}

Opportunities for socialisation, assessment and skills development were key themes identified. MSST was identified by all interviewees as a tool that could be used to support socialisation, and storytelling sessions were structured to maximise opportunities and enjoyment in this area.

'I mean, they are so separate my guys! You can see, they are, with all this equipment... But it's a time when they can actually be together, they all get to see the objects going around - well, two of them can. But they can all hear and feel that we're all sharing stuff, so I think on a very limited level it gives them a chance to come together as a group.'

Though MSST sometimes fulfilled a leisure function, the use of the approach was explicitly linked to assessment and learning. All teachers interviewed identified MSST as a valuable vehicle to support the assessment of their studentsparticularly with regard to the $P$ Scales (QCA, 2009; QCDA, 2011) -and with regard to individual targets and goals. 
'I look at the children's assessments and targets...I look at fine motor, communication, cognitive, and so on. Each specific to each child in the class... I set my goals, I develop my story. That's how I do it.'

'When we devise or adapt a story we integrate their targets in it. So...somebody's target could be to hold the flashlight for three to five seconds...and somebody else's would be to move a blanket to look for something underneath it. Throughout the story we try to find as many times... like three to four times for them to practice that skill. And somebody else's might be to reach for something that is of interest or to track the light. We use the targets and plan around them.'

The typical structure of a multi-sensory story - with objects being presented to students in sequence, and with children exploring each object - was identified as being helpful in the development of memory, anticipation, requesting and focusing attention: the whole range of skills and behaviours identified within P1 to P3 of the P Scales (QCA, 2009). The interactive and exploratory nature of MSST provided multiple communication opportunities, both to communicate with a range of adults and to express their preferences, supporting the development of a sense of agency and empowerment.

'I don't want it... push it away. That's good because they are telling you that they don't like it. It's all communication. I'll know if they don't like it and that's very important...because often they won't be given those choices.'

Though most storytelling sessions observed were group activities, respondents stressed time and again the importance of individualisation. The same story was presented to different students in different ways, depending on individual preferences, tolerances and needs - for example, different sized versions of the same object take account of students' fine motor skills. Teachers told how they individualised and differentiated 'naturally - you do it as part of what you do all day, every day'. 'Home-made' stories, commercially-produced materials and scripts were all adapted to address the experience of each student and to ensure their appropriateness.

'This object (a steering wheel) didn't work for her to represent a car...she's no sight and doesn't know what a steering wheel is. So... What will she will be familiar with? Whenever she's being driven, in a car or when she comes to school on the school bus, she'll be fastened in with a seat belt. There'll be a feeling and she can hear the click. So we used part of a seatbelt in the story.'

'For me, the scripts are all about the ideas. I always look at adapting it. So given the specific needs of the students I've got, I might also introduce things like choices with PECS symbols or photographs, embellishing the story and making it even more appropriate to the students' needs, their targets and so on.'

The use of MSST was affected by a number of factors, both internal to the teacher and external. Key external factors were time, resources and staffing 
levels. Staff in one setting also identified that their perceptions regarding expectations of external inspectors impacted on how MSST was delivered:

'OFSTED requires that your students are doing something all the time. They will no longer accept something going around a group one at a time.'

However, underpinning all of the different ways that MSST was used and adapted lay the specific judgements and decisions of teachers: how, where, when, why, and with whom to use them. All interviewees considered MSST a pedagogic activity, identifying a range of factors that informed the choices they made about its use. These included teachers' personal attributes (such as extroversion or imaginativeness), their training and professional background, and their individual teaching styles. Some enjoyed using ready-made stories or scripts as a basis for MSST, while others preferred to make their own.

'It's good to have some ideas as a starting point, but you need to individualise it for your children...and I do quite enjoy the idea of coming up with the story myself...'

A minority had undertaken training in MSST, whilst at university, or via their local authority or a charity. Most however had not, and based their practice on their natural storytelling style, their observations of others or on mentoring from more experienced staff.

'I think really here it's about drawing on other teachers, more experienced storytellers...drawing on their knowledge and their experience and then sharing really good practice.'

\section{Discussion}

This analysis identifies that MSST was viewed positively, and that it was considered to contribute to the curriculum access, assessment, learning and socialisation of students across a wide range of SEN - and in particular, to the experience of students with PMLD. MSST was used in a wide variety of ways for a wide variety of purposes. In many respects such findings seem unsurprising and indeed to be expected with regard to an aspect of teaching practice. As one respondent stated, 'I mean, that's just teaching, right?' However, comparison of these findings with extant literature regarding MSST identifies noteworthy points of divergence regarding the function, design and delivery of MSST. These points merit discussion, and are indicative of a deeper issue regarding research, evidence and practice in education.

\section{Function of MSST}

Much of the research literature concerning MSST has focused on use of the approach to deal with individual problems or issues (Lambe and Hogg, 2013; Lambe et al., 2014; Watson, 2002; Young et al., 2011). In stark contrast, no teachers interviewed for this study had used storytelling in this way. In the only case where such an individual outcome was identified (a boy on the autism spectrum, whose enjoyment of a story about a haircut had enabled him to tolerate going to the barber's) this was identified by his teacher as a 
'serendipitous bonus'. The ways that MSST is used in the extant literature and the ways it was used by these teachers appear to differ.

\section{Design and delivery of MSST}

Much of the literature regarding MSST stresses the importance of adherence to identified guidelines. Vlaskamp et al. (2011) note positively that PAMIS' guidelines for MSST (in ten Brug et al., 2012, p.353) present opportunities for the development of an empirical evidence base for the approach, due to the explicit guidelines provided. These relate both to the construction of a multisensory story (including the maximum number of sentences, maximum number of sentences per page, the number of stimuli per page and the requirement that a white board is used) and to how the story should be told. Consistency is also emphasised in the guidelines to commercially-produced stories (Bag Books, 2011; Grace, 2014; ten Brug et al., 2012). However, this is very different from the way that the professionals who participated in this current study approached MSST. To them, it is 'a tool that you have to adapt and individualise to the needs of the kids' and 'there is no real right or wrong way to do it.'

Ten Brug et al. (2012), evaluating 49 multi-sensory stories for individuals with PMLD against the PAMIS guidelines, found that in only $1.3 \%$ of storytelling sessions were the stories read 'as intended' (i.e. adhering to the PAMIS guidelines regarding design and delivery). Within this current study, none of the 'home-made' multi-sensory stories observed aligned with these guidelines, either with regard to their construction (for example, none were mounted on white boards) or with regard to their delivery - and teachers were quick to identify that they varied how they would tell a story dependent upon their ongoing assessment of the lesson and their students' needs.

'When you are telling a multi-sensory story you're continually adapting, assessing and making judgements. Those types of things that you're always doing as a teacher.'

Moreover, when using commercially-produced stories, teachers amended and adapted both stories and/or materials based on their pedagogic judgement. Objects provided or suggested were replaced by others that teachers considered more meaningful; multiple objects might be used to reduce waiting or to allow for individuals' extended processing time. Furthermore, teachers happily recycled and re-used preferred materials for multiple functions, utilising them within other sensory learning activities as well as MSST).

'I can use bits and bobs from the ready-made stories for other things... if I'm doing something else and I know that there is something that I need for it, then I take it out and use it.'

\section{Evidence base for MSST}

These issues raise an interesting question. Is the development of an empirical, quantitative evidence base for MSST a realistic aim? If ten Brug et al. (2012) identify that $98.7 \%$ of observed storytelling sessions fail to adhere to the guidelines, might it not be worth considering whether these guidelines are overly prescriptive and unhelpful? Instead, the literature labels those using MSST in a more fluid way (and who way well have more in-depth knowledge of individual 
children than researchers) as 'well-meaning professionals who do not have the background, the skills or the inclination to carry out scientific studies (Vlaskamp et al., 2011, p.107)'.

It may at this point be worthwhile considering the findings of Reynhout and Carter's (2006) meta-analysis of 16 studies investigating the use of the 'Social Stories $^{\mathrm{TM}}$ ' approach with individuals on the autism spectrum. Social Stories ${ }^{\mathrm{TM}}$, as defined by Gray (2000), should adhere to a strict formula regarding the ratio of directive, descriptive, perspective, cooperative and affirmative sentences included in each story. However, Reynhout and Carter (2006) identified that, stories used 'in the real world' often varied considerably from the prescribed construction; furthermore they found that there was no evidence that this had a negative impact. They state that

'...it is unclear from the present review that the prescribed (and complex) story construction is necessary to the efficacy of the intervention, which components are critical to effectiveness and whether Social Stories necessarily add to the effectiveness of other interventions. The confounding of Social Story ${ }^{\mathrm{TM}}$ interventions with other strategies is a problem (Reynhout and Carter, 2006, p.465)'.

It is certainly the case that those individuals - with PMLD or other SEN - who are typically experiencing MSST may well be receiving a number of other interventions - educational, pharmacological, dietary, physiotherapeutic - or that their experience of MSST may be confounded by myriad factors - ill heath, epilepsy, hunger or tiredness, to name but a few. As one respondent noted,

'we use multi-sensory stories along with a whole range of other strategies...phonics boxes, Big Macks, structured teaching with visual teaching strategies, PECS, symbols, objects...'

We would suggest that, taking account of the range of factors identified above, attempts to identify the specific impact of MSST sessions upon the learning and development of these students may well be impracticable.

\section{Evidence-based or evidence-informed practice?}

Comparison of the data collected in this study with much of the research in this field suggests that the desire to develop a quantitative evidence base regarding practice in this area may be leading to artificial and unnecessary limits being placed around MSST, what it comprises and how it should be undertaken. Much of the published research fails to acknowledge the breadth and range of ways in which MSST may be used. Moreover the emphasis on adherence to guidelines fails to acknowledge the pedagogic skills of these professionals, or the ways in which teachers are reflecting in action (Schön, 1982) and adapting their practice in vivo according to those reflections.

Furthermore it may be that seeking to claim MSST (or indeed any educational intervention) as an evidence-based practice is ill-judged. The argument has long been made that teaching is a practical art, 
'...a process that calls for intuition, creativity, improvisation and expressiveness - a process that leaves room for departures from what is implied by rules, formulas and algorithms (Gage, 1978, p.15)'.

Equally, Hammersley (2005) has identified that 'pedagogic practice' (which describes most if not all of the storytelling observed in this study) is never fully or directly based on research evidence, as this is always of necessity filtered through the individual teacher's experience and understanding and each unique context. Thomas (2012) has conceptualised teachers' knowledge as 'craft knowledge' derived from and informed by 'evidence amassed and adduced out of practical experience (p.41)'. Hedges (2012) further notes that teachers' informal 'funds of knowledge' - the knowledge gained through their own education, their training, and their teaching experience - are a primary influence on the decisions that teachers make, and are likely to be prioritised over theory or research protocols in pedagogic decision-making.

Thomas (2012) argues that the demand for more 'scientific' research in education (see for example, Goldacre, 2013) is based upon inaccurate presumptions about what 'being scientific' means, asserting that scientific research is invariably and inevitably 'fluid and multifarious (p.28)', utilising methods that are appropriate and fit for purpose dependent on the phenomenon being studied. Moreover, echoing Reynhout and Carter (2006), he further asserts that the 'undeniably large number of factors that come into play in education should make us instinctively cautious about seeking generalisability and causality' with regard to the impact of any intervention or technique (Thomas, 2012, pp.31-32). We would support this more cautious and less restrictive approach both to educational research in general and that focused on MSST in particular.

Cochran-Smith and Lyttle (2006) have written of the need for 'deliberative pedagogies', whereby teachers work together sharing their experiences, feedback and ideas to develop and inform professional practice; and Wenger (1999) has identified the importance of 'communities of practice' in supporting learning and teaching activity. Professional journals such as PMLD Link perform an important role in supporting and maintaining such a community of practice in this field; and classroom-based studies such as those by Arnold (2014) and Grace (2014) are making a valuable contribution regarding MSST. Such studies identify how educators are using MSST in the field, and offer others the opportunity to consider how their practice may relate to other settings, providing an opportunity to strengthen the knowledge base about this shared approach.

In her original publication on MSST, Fuller (1990) urged teachers to consider the stories as 'a starting point (to) encourage story-tellers with ideas of their own to access this area of the curriculum to this group of pupils' (Fuller, 1990, p3). MSST - like all areas of teaching - seems to be most useful to teachers and learners when it is implemented through 'local hermeneutics', the rules of thumb that inform how teachers interpret, analyse and respond to what is going on in the classroom (Thomas, 2012). Such hermeneutics are built up over time and based on individual teachers' knowledge and experience informing what needs to be done, where and when. What works for one teacher in one classroom may (or may not) work for another. What is effective for one student may be ineffective with another. Indeed, an activity that might be enjoyable and effective for a 
student in the morning might not 'work' for the same student the same afternoon, dependent upon the host of variables that may come into play. These issues must be acknowledged and remembered. We hope that this overview of practice in five schools will encourage further teachers to consider using MSST across the curriculum and beyond in ways that are appropriate for the students with whom they work, and to share their experience of using this creative and exciting approach within the wider community of practice.

\section{References}

Arnold, A. (2013) The Little Book of Multi-Sensory Stories. Husbands Bosworth: Featherstone Education.

Arnold, J. (2014) Developing Innovations - investigating the impact of a $1: 1$ multi-sensory story in comparison with ongoing sensory sessions: a case study investigation. PMLD Link, 26 (3), 14-16.

Bag Books (2011) Training Notes. London: Bag Books.

Basit, T.N. (2003) Manual or electronic? The role of coding in qualitative data analysis, Educational Research, 45 (20, 143-154.

Boer, N. \& Wikkerman, C. (2008) Multi-Sensory Storytelling (MSST) makes sense. Markant, Kenniskatern, 5/2008, 8-11.

British Educational Research Association (2011) Ethical Guidelines for Education Research.

Cochran-Smith, M., \& Lytle, S. L. (2006) Troubling images of teaching in No Child Left Behind. Harvard Educational Review, 76 (4), 668-697.

Fornefeld, B. (2013) Storytelling with all our senses: mehr-Sinn $®$ Geschichten. In N. Grove (ed) Using Storytelling to Support Children and Adults with Special Needs, pp78-85. Abingdon: Routledge.

Fuller, C. (1990) Tactile Stories: a do-it-yourself guide to making 6 tactile books. London: Resources for Learning Difficulties - The Consortium.

Fuller, C. (1999) Fiction for adults with Profound Learning Difficulties. PMLD Link, $12(1), 11-13$.

Fuller, C. (2013) Multi-sensory stories in story-packs. In N. Grove (ed) Using Storytelling to Support Children and Adults with Special Needs, pp72-77. Abingdon: Routledge.

Gage, N.L. (1978) The Scientific Basis of the Art of Teaching. New York: Teachers College Press.

Goldacre, B. (2013) Building Evidence into Education [online]. Available from: http://media.education.gov.uk/assets/files/pdf/b/ben\%20goldacre\%20pa per.pdf [Accessed 22/7/2013].

Grace, J. (2014) Sensory Stories for Children and Teens with Special Educational Needs: A Practical Guide. London: Jessica Kingsley.

Gray, C. (2000). The New Social Story Book. Arlington, TX: Future Horizons, Inc. Grove, N. (2014) Personal oral narratives in a special school curriculum: an analysis of key documents. British Journal of Special Education, 41(1), 624.

Grove, N., Harwood, J., Henderson, E., Park, K. \& Bird, R. (2015) Literature and stories in the lives of learners with SLD/PMLD. In P. Lacey, R. Ashdown, P. Jones, H. Lawson \& M. Pipe (eds) The Routledge Companion to Severe, Profound and Multiple Learning Difficulties, pp305-311. Abingdon: Routledge.

Hammersley, M. (2005) The myth of research-based practice: the critical case of educational inquiry. International Journal of Social Research Methodology, $8(4), 317-330$. 
Hedges, H. (2012) Teachers' funds of knowledge: a challenge to evidence-based practice. Teachers and Teaching: Theory and Practice, 18 (1), 7-24.

King, N. (2004) Using templates in the thematic analysis of text. In C. Cassell \& G. Symons (eds) Essential Guide to Qualitative Methods in Organizational Research. London: Sage.

Lambe, L. \& Hogg, J. (2011) Multi-sensory storytelling: PAMIS' practice, experience and research findings. In B. Fornefeld (ed) Mehrsinnliches Geschichtenerzählen - eine Idee setzt sich durch, pp15-40. Berlin: LIT Verlag.

Lambe, L. \& Hogg, J. (2013) Sensitive stories: tackling challenges for people with profound intellectual disabilities through multisensory storytelling. In N. Grove (ed) Using Storytelling to Support Children and Adults with Special Needs, pp86-94. Abingdon: Routledge.

Lambe, L., Fenwic, M., Young, H. \& Hogg, J. (2014) The use of a personalised multi-sensory story to prepare a young man with profound intellectual disabilities and autism for oral health care: a case study. Journal of Disability and Oral Health, 15 (4), 154-158.

Lawson, H.A., Layton, L., Goldbart, J., Lacey, P. \& Miller, C. (2012) Conceptualisations of literacy and literacy practices for children with severe learning difficulties, Literacy, 46(2), 101-108.

Male, D. (2015) Learners with SLD and PMLD: provision, policy and practice. In P. Lacey, R. Ashdown, P. Jones, H. Lawson \& M. Pipe (eds) The Routledge Companion to Severe, Profound and Multiple Learning Difficulties, pp9-18. Abingdon: Routledge.

Mills, A.J., Durepos, G. \& Wiebe, E. (2010) Encyclopedia of Case Study Research. London: Sage.

Park, K. (2013) Interactive storytelling. In N. Grove (ed) Using Storytelling to Support Children and Adults with Special Needs, pp40-47. Abingdon: Routledge.

Penne, A. \& Maes, B. (2011) Multi-sensory storytelling: current research results in Flanders. In B. Fornefeld (ed) Mehrsinnliches Geschichtenerzählen eine Idee setzt sich durch, pp63-92. Berlin: LIT Verlag.

Penne, A., ten Brug, A., Munde, V., van der Putten, A., Vlaskamp, C. \& Maes, B. (2012) Staff interactive style during multisensory storytelling with persons with profound intellectual and multiple disabilities, Journal of Intellectual Disability Research, 56 (2), 167-178.

Qualifications and Curriculum Authority (2009) The P Scales: Level Descriptors P1 to P8. London: QCA.

Qualifications and Curriculum Development Agency (2011) Using the P Scales to assess pupils' progress. Coventry: QCDA.

Reynhout, G. \& Carter, M (2006) Social Stories ${ }^{\mathrm{TM}}$ for children with disabilities. Journal of Autism and Developmental Disorders, 36 (4), 445-469.

Schön, D. (1983) The Reflective Practitioner: How Professionals Think in Action. New York: Basic Books.

ten Brug, A., van der Putten, A., Penne, A., Maes, B. \& Vlaskamp, C. (2012) Multi-sensory storytelling for persons with profound intellectual and multiple disabilities: an analysis of the development, content and application in practice. Journal of Applied Research in Intellectual Disabilities, 25 (4), 350-359.

Thomas, G. (2012) Changing our landscape of inquiry for a new science of education. Harvard Educational Review, 82 (1), 26-51. 
Vlaskamp, C., ten Brug, A. \& van der Putten, A. (2011) Multi-sensory storytelling in the Netherlands. In B. Fornefeld (ed) Mehrsinnliches Geschichtenerzählen - eine Idee setzt sich durch, pp107-122. Berlin: LIT Verlag.

Watson, M. (2002) Developing Literacy skills through Multi-sensory Story-telling in Children and young Adults with Profound and Multiple Learning Disabilities. Dundee: University of Dundee.

Wenger, E. (1999) Communities of Practice: Learning, Meaning, and Identity (Learning in Doing: Social, Cognitive and Computational Perspectives). Cambridge: Cambridge University Press.

Wiles, R. (2013) What are Qualitative Research Ethics? London: Bloomsbury.

Young, H. \& Lambe, L. (2011) Multi-sensory storytelling: for people with profound and multiple learning disabilities. PMLD Link, 23 (1), 29-31.

Young, H., Fenwick, M., Lambe, L. \& Hogg, J. (2011) Multi-sensory storytelling as an aid to assisting people with profound intellectual disabilities to cope with sensitive issues: a multiple research methods analysis of engagement and outcomes. European Journal of Special Needs Education, 26 (2), 127142. 